Article

\title{
Antioxidant Capacity and Hepatoprotective Role of Chitosan-Stabilized Selenium Nanoparticles in Concanavalin A-Induced Liver Injury in Mice
}

\author{
Kaikai Bai $^{1,2, *}$, Bihong Hong ${ }^{1,2}$, Jianlin He ${ }^{1,2} \mathbb{D}$ and Wenwen Huang ${ }^{1,2}$ \\ 1 Third Institute of Oceanography, Ministry of Natural Resources, Xiamen 361005, China; \\ bhhong@tio.org.cn (B.H.); hejianlin@tio.org.cn (J.H.); wwhuang@tio.org.cn (W.H.) \\ 2 Technology Innovation Center for Exploitation of Marine Biological Resources, Ministry of Natural \\ Resources, Xiamen 361005, China \\ * Correspondence: kkbai@tio.org.cn; Tel.: +86-592-2195309
}

Received: 24 February 2020; Accepted: 20 March 2020; Published: 23 March 2020

\begin{abstract}
Selenium nanoparticles (SeNPs) have attracted wide attention for their use in nutritional supplements and nanomedicine applications. However, their potential to protect against autoimmune hepatitis has not been fully investigated, and the role of their antioxidant capacity in hepatoprotection is uncertain. In this study, chitosan-stabilized SeNPs (CS-SeNPs) were prepared by means of rapid ultra-filtration, and then their antioxidant ability and free-radical scavenging capacity were evaluated. The hepatoprotective potential of a spray-dried CS-SeNPs powder against autoimmune liver disease was also studied in the concanavalin A (Con A)-induced liver injury mouse model. CS-SeNPs with size of around $60 \mathrm{~nm}$ exhibited acceptable oxygen radical absorbance capacity and were able to scavenge DPPH, superoxide anion, and hydroxyl radicals. The CS-SeNPs powder alleviated Con A-caused hepatocyte necrosis and reduced the elevated levels of serum alanine transaminase, aspartate transaminase, and lactic dehydrogenase in Con A-treated mice. These results suggest that the CS-SeNPs powder protected the mice from Con-A-induced oxidative stress in the liver by retarding lipid oxidation and by boosting the activities of superoxide dismutase, glutathione peroxidase, and catalase, partly because of its ability to improve Se retention. In conclusion, SeNPs present potent hepatoprotective potential against Con A-induced liver damage by enhancing the redox state in the liver; therefore, they deserve further development.
\end{abstract}

Keywords: selenium nanoparticles; liver injury; antioxidant; concanavalin A

\section{Introduction}

Selenium (Se) is an indispensable trace element required for animals and humans. It is a dietary nutrient playing an important role in many aspects of health [1,2], in particular for its antioxidant activity [1-3]. It is an integral element of the catalytic site of more than 25 selenoproteins and enzymes in the human body, and it plays an essential role in protecting cells and tissues from oxidative injury $[2,3]$. Se deficiency might break the balance between antioxidants and oxidants in the body, which can increase oxidation-associated risks, especially when the body is challenged by oxidative stress [1-3]. Generally, individuals do not require Se supplementation if a normal diet containing adequate Se is available, while people living in regions of low environmental selenium level (e.g., mainland China and Egypt) may be suffering from insufficient Se intake due to the low Se content in their food. It is necessary to meet the daily requirement of this nutrient by Se supplementation, especially for those subjected to Se deficiency [1-4].

Se deficiency is associated with numerous diseases including liver damage. Oxidative stress caused by various stimuli is an important aspect of many liver diseases elicited by toxic chemicals [5], 
autoimmune response [5,6], anoxic/reoxygenation injury [6], viral infection [5,6], alcoholic injury [6,7], and so on. Recently, an increasing number of studies have indicated that liver injury can be induced by Se deficiency, and Se supplementation is able to recover the hepatic damage [8-12]. More importantly, some hepatic diseases caused by alcohol, toxic elements, heavy metals, and chemotherapeutic drugs can be attenuated by extra Se supplementation [8-12]. It has been reported that Se might also help treat individuals with liver diseases such as hepatocellular carcinoma $[13,14]$. The antioxidant potential of Se plays an important part in the hepatoprotective role of this element.

Recently, selenium nanoparticles (SeNPs)—elemental, nanosized selenium particles-have attracted increasing attention due to their excellent properties and favorable biological activities $[3,15,16]$. SeNPs are considered to be a prospective Se supplement, since they have exhibited great potential for use in nutritional supplementation, chemoprevention, chemical therapy, and nanomedicine delivery applications $[3,15,16]$. The hepatoprotective effect of SeNPs seems to be promising, as SeNPs can protect animals from chemicals- or pathogen-induced hepatic damage through their antioxidant capacity [17-20]. However, the hepatoprotective effect of the nanoparticles has not been fully studied, especially when liver injury is caused by other factors such as an autoimmune disorder. In fact, whether the antioxidant activities of SeNPs may also protect from immune disorder-caused liver injury is uncertain.

Chitosan (CS), the only positively charged polysaccharide in nature, has been extensively explored for its potential use in drug delivery systems [21]. In this study, chitosan-stabilized selenium nanoparticles, namely CS-SeNPs, were prepared by means of rapid ultra-filtration (UF), and then the antioxidant activity and free-radical scavenging capacity of CS-SeNPs were evaluated. Furthermore, the hepatoprotective effect of dried CS-SeNPs powder against autoimmune liver disease was studied by using mice with concanavalin A (Con A)-induced liver injury, which are a model of this disease.

\section{Materials and Methods}

\subsection{Materials and Animals}

\subsubsection{Materials}

CS of food grade $(90.32 \%$ deacetylated, average molecular weight of $37 \mathrm{kDa})$ was provided by Aoxin Pharmaceutical Co. Ltd. (Taizhou, China). The compounds 2,2'-azobis-(2-amidinopropane)-dihydrochloride (AAPH), 1,1-diphenyl-2-picrylhydrazyl (DPPH), fluorescein disodium, pyrogallic acid, and 6-hydroxy-2,5,7,8-tetramethylchroman-2-carboxylic acid (Trolox) of high purity were obtained from Sigma-Aldrich (St.Lousi, MO, USA). Glycyrrhizic acid (GA) was purchased from Xi'an Liqun Pharmaceutical Co. Ltd. (Xi'an, China). Ascorbic acid (VC), sodium selenite, acetic acid, and other reagents of analytical grade were obtained from local commercial suppliers (Sinopharm Chemical Reagent Co., Ltd., Shanghai, China, etc). The assay kits for measuring protein content, alanine transaminase (ALT), aspartate transaminase (AST), lactic dehydrogenase ( $\mathrm{LDH}$ ), glutathione (GSH), thiobarbituric acid-reactive substances (TBARS), superoxide dismutase (SOD), catalase (CAT), and glutathione peroxidase (GSH-Px) were supplied by Jiancheng Bioengineering Institute (Nanjing, China).

\subsubsection{Animals}

Male Kunming (KM) mice (8-10 weeks old, 18-22 g body weight) of specific-pathogen-free (SPF) grade were provided by Laboratory Animal Center, Shenyang Pharmaceutical University (Shenyang, China) with the license No. SCXK (Liaoning) 2015-0001. Mice were housed in a standardized sterile animal room with controlled temperature $\left(25 \pm 2{ }^{\circ} \mathrm{C}\right)$ and humidity $(50 \% \pm 10 \%)$ and light/dark cycle $(12 \mathrm{~h} / 12 \mathrm{~h})$. The procedures utilized in the animal experiment were approved by the Animal Ethics Committees at Shenyang Pharmaceutical University (ethical committee approval 
number: SYPU-IACUC-C2017-5-17-104, Date (17/5/2017)). They were also compliant with the general recommendations and provisions of the Chinese Experimental Animals Administration Legislation.

\subsection{Preparation, Characterization, and Stabilization of SeNPs}

CS-SeNPs were synthesized in the presence of CS, as described in previous studies $[15,16]$. A CS-SeNPs colloid was obtained with the final concentrations of Se, CS, and VC of $4 \mathrm{mM}, 0.1 \%(w / w)$, and $16 \mathrm{mM}$, respectively. The colloid was purified through UF in a $0.5 \%(\mathrm{w} / \mathrm{w})$ acetic acid solution, unless the permeate did not fade the color of a $1 \mu \mathrm{mol} / \mathrm{L}$ potassium permanganate $\left(\mathrm{KMnO}_{4}\right)$ solution within 20 min. A membrane filtration device (FlowMem-0015, Starmem Scitechnology, Xiamen, China) equipped with a polyethersulfone (PES) membrane (molecular weight cutoff (MWCO) $=8 \mathrm{kDa}$, UE008, GE, USA) was utilized to perform UF. After that, a purified CS-SeNPs colloid was obtained, and the content of CS-SeNPs was measured by lyophilizing the colloid. The size distribution, morphological characteristics, and zeta-potential of SeNPs were also investigated as previously described $[15,16]$. In addition, part of the purified CS-SeNPs were added to another stock of acetic acid solution containing CS, and then the mixture was spray-dried to acquire a dried CS-SeNPs powder, as reported in our previous studies $[15,16]$. Se content was determined by using inductively coupled plasma mass spectrometry (ICP-MS) [22].

\subsection{Oxygen Radical Absorbance Capacity (ORAC) Test}

The ORAC assay was performed by using fluorescein disodium as the probe molecule according to López-Alarcón [23,24], with some modification. Briefly, stock solutions of fluorescein disodium $(50 \mu \mathrm{M})$ and AAPH $(30 \mathrm{mM})$ were prepared freshly in deionized water. Reaction mixtures containing AAPH $(20 \mu \mathrm{L})$ and fluorescein salt $(20 \mu \mathrm{L})$, with or without the tested samples, were incubated in phosphate-buffered solution (PBS, $50 \mathrm{mM}, \mathrm{pH} 7.4$ ) at $37^{\circ} \mathrm{C}$. The consumption of fluorescein, dependent on its incubation with AAPH, was evaluated from fluorescence measurements. The fluorescence measurements were conducted by utilizing a microplate reader (SpectraMax M5, Molecular Devices, CA, USA) equipped with a Softmax Pro software program, and the progressive decrease of fluorescence intensity (excitation: $485 \mathrm{~nm}$; emission: $538 \mathrm{~nm}$ ) was recorded. The ratio of current fluorescence $(\mathrm{F})$ to initial fluorescence $\left(\mathrm{F}_{0}\right)$, indicated as $\mathrm{F} / \mathrm{F}_{0}$, was plotted as a function of time. The area under the curve (AUC) was integrated up to the time necessary for $\mathrm{F} / \mathrm{F}_{0}$ to reach the value of 0.005 . Each area was employed to obtain the relative net AUC value as follows:

$$
\text { Relative Net } \mathrm{AUC}=\left(\mathrm{AUC}_{\text {sample }}-\mathrm{AUC}_{\mathrm{AAPH}+}\right) / \mathrm{AUC}_{\mathrm{AAPH}+}
$$

where $\mathrm{AUC}_{\text {sample }}$ is the $\mathrm{AUC}$ of a sample, and $\mathrm{AUC}_{\mathrm{AAPH}+}$ is the $\mathrm{AUC}$ of the $\mathrm{AAPH}$ control without any sample.

After that, the relative net AUC was plotted as a function of the concentration of the sample, and the slope value (SV) of each AUC curve was measured through linear regression. The ORAC of each sample was calculated as follows:

$$
\mathrm{ORAC}=\mathrm{SV}_{\text {sample }} / \mathrm{SV}_{\text {Trolox }}
$$

where $\mathrm{SV}_{\text {Trolox }}$ is the slope value of the AUC for Trolox; $\mathrm{SV}_{\text {sample }}$ is the slope value of the $\mathrm{AUC}$ for the examined sample.

\subsection{Free-Radical Scavenging Tests}

The DPPH radical $(\bullet \mathrm{DPPH})$ and superoxide anion radical $\left(\bullet \mathrm{O}_{2}^{-}\right)$scavenging assays were performed as previously described [25] to measure the antioxidant abilities of the tested samples. In addition, the hydroxyl radical $(\bullet \mathrm{OH})$ scavenging activity was determined according to Peralta [26], with some modification. Fenton reagent (ferric sulphate/hydrogen peroxide, $\mathrm{FeSO}_{4} / \mathrm{H}_{2} \mathrm{O}_{2}$ ) was used 
to generate $\bullet \mathrm{OH}$, while salicylic acid (SA) was utilized as an $\bullet \mathrm{OH}$-trapping reagent to absorb the generated $\bullet \mathrm{OH}$. In brief, to a $1 \mathrm{M}$ acetic acid/sodium acetate solution ( $\mathrm{pH}$ 3.5) the tested sample was added at various concentrations, followed by the addition of Fenton reagent and SA. The mixture was quickly adjusted to $10 \mathrm{~mL}$ with ethanol, reaching final concentrations of $\mathrm{FeSO}_{4}, \mathrm{H}_{2} \mathrm{O}_{2}$, and SA of $0.36 \mathrm{mM}, 0.1 \mathrm{mM}$, and $0.54 \mathrm{mM}$, respectively. After incubation for $30 \mathrm{~min}$ at $25^{\circ} \mathrm{C}$, the absorbance of the solution was recorded at $520 \mathrm{~nm}$. The $\bullet \mathrm{OH}$ scavenging ability was calculated as follows:

$$
\text { Scavenging ability }(\bullet \mathrm{OH})=\left(\mathrm{A}_{1}-\mathrm{A}_{2}+\mathrm{A}_{3}\right) / \mathrm{A}_{1} \times 100 \%
$$

where $A_{1}$ is the absorbance of the control solution containing Fenton reagent and SA; $A_{2}$ is the absorbance of the mixture of sample and reagents; $A_{3}$ is the absorbance of the sample without any reagent.

\subsection{Animal Experiments}

\subsubsection{Experiment Design and Animal Grouping}

A Con A challenge test was conducted as described by Zhang [27] and Anraku [28], with some changes. Briefly, 80 male KM mice were randomly divided into 8 groups (10 mice each): Control, Model, VC, GA, CS, and three CS-SeNPs groups (L-Se, M-Se, and H-Se). The mice were daily administered the above treatments by gavage for 35 days (shown in Table 1), and their body weight (bw) was monitored throughout the experiment. Except for the normal control, mice were also intravenously (iv) administrated Con A (20 mg/kg bw) in their tail veins after the last pre-treatment. The mice in the control group were given the same volume of sterile normal saline instead of Con A. The mice were allowed free access to water. Eight hours later, the mice were anesthetized through intraperitoneal (ip) injection of aqueous pentobarbital sodium $(60 \mathrm{mg} / \mathrm{kg} \mathrm{bw})$. The blood of the animals was collected into heparin-free tubes to acquire the sera, while tissue samples were also obtained.

Table 1. Administration of the treatments during the concanavalin A (Con A) challenge experiment (Kunming (KM) mice, $n=10)$.

\begin{tabular}{ccc}
\hline Group & Pre-treatment (once daily, ig, Day 1-35) & Treatment (once, iv, Day 35) \\
\hline Control & Normal saline & Normal saline \\
Model & Normal saline & Con A $(10 \mathrm{mg} / \mathrm{kg} \mathrm{bw})$ \\
GA & Glycyrrhizic acid $(10 \mathrm{mg} / \mathrm{kg} \mathrm{bw})$ & Con A $(10 \mathrm{mg} / \mathrm{kg} \mathrm{bw})$ \\
CS & Chitosan $(1.2 \mathrm{mg} \mathrm{kg-1} \mathrm{bw)}$ & Con A $(10 \mathrm{mg} / \mathrm{kg} \mathrm{bw})$ \\
L-Se & Dried CS-SeNPs power $(0.6 \mathrm{mg} \mathrm{kg}-1 \mathrm{bw})$ & Con A $(10 \mathrm{mg} / \mathrm{kg} \mathrm{bw})$ \\
M-Se & Dried CS-SeNPs power $(1.2 \mathrm{mg} \mathrm{kg}-1 \mathrm{bw})$ & Con A $(10 \mathrm{mg} / \mathrm{kg} \mathrm{bw})$ \\
H-Se & Dried CS-SeNPs power $(2.4 \mathrm{mg} \mathrm{kg}-1 \mathrm{bw})$ & Con A $(10 \mathrm{mg} / \mathrm{kg} \mathrm{bw})$ \\
\hline
\end{tabular}

Note: bw, body weight; ig, intragastrically; iv, intravenously; SeNPs; selenium nanoparticles

\subsubsection{Liver Histopathology Assessment}

Fresh tissue obtained in the middle of the hepatic left lateral lobe was preserved in $4 \%$ paraformaldehyde for at least $24 \mathrm{~h}$. After that, the specimen was embedded in paraffin and then sectioned at a thickness of $\sim 5 \mu \mathrm{m}$ for hematoxylin and eosin ( $\mathrm{H} \& \mathrm{E})$ dual staining. The tissue damage was observed by light microscopy and was graded by an independent viewer blinded to the treatment, as described by $\mathrm{Wu}$ [29] with slight modifications. Briefly, hepatic injury was scored on the basis of the severity and the area of necrosis as follows: 0 (normal); 1 (rare necrosis); 2 (necrosis $<25 \%$ ), 3 (25\% $\leq$ necrosis $<50 \%), 4(50 \% \leq$ necrosis $<75 \%)$ and $5(75 \% \leq$ necrosis $)$. 


\subsubsection{Determination of Se Deposition}

Se in the liver blood was determined by ICP-MS assay, as previously described $[15,16]$. Briefly, the sample was mixed with $\mathrm{HNO}_{3}$ and $\mathrm{H}_{2} \mathrm{O}_{2}$, and the mixture was digested in a microwave device (JK-MDA-23, Shanghai, China). After digestion, the Se content in the digested solution was determined by ICP-MS (7700X, Agilent, CA, USA).

\subsubsection{Biochemical Analysis}

Fresh liver samples were rinsed with cold normal saline and then homogenized in ice-cold saline. After immediate centrifugation $\left(10,000 \times g, 4{ }^{\circ} \mathrm{C}, 10 \mathrm{~min}\right)$, the supernatants were collected. After that, the levels of AST, ALT, LDH, TBARS (malondialdehyde equivalent), GSH, GSH-Px, SOD, and CAT, were measured in the liver supernatants and sera, following the instructions of the commercial kits.

\subsection{Statistical Analysis}

For all experiments, data are presented as mean \pm standard deviation (SD). The difference between three or more groups was analyzed through the one-way analysis of variance (one-way ANOVA) test followed by multiple comparisons. SPSS software program (version 17.0 for Windows, Microsoft, Redmond, WA, USA) was used for data processing, and a $p$ value of $<0.05$ was regarded as statistically significant.

\section{Results and Discussion}

\subsection{UF-assisted Preparation of CS-SeNPs}

Many polysaccharides, such as chitosan, alginate, gum arabic, and sialic acid, have been used to synthesize and stabilize SeNPs, and SeNPs of various shapes have been obtained [15,16,30-33]. These polysaccharides are able to control the synthesis, morphological characteristics, and structure of SeNPs and might also stabilize the nanoparticles. However, it is challenging to remove the synthesis byproducts from SeNPs. In some previous reports, a washing process by high-speed centrifugation was repeated several times to eliminate the unwanted impurity [34-36]. In other studies, dialysis was utilized to purify the synthesized SeNPs, followed by a lyophilization process to obtain the final SeNPs product $[15,16,30,32,33]$. However, these methods are impracticable for industrial production due to their low efficiency, limited production scale, and high cost. Besides, the stability of SeNPs should be taken into account during the purification process.

Herein, UF was utilized, instead of dialysis or centrifugation, to purify CS-SeNPs. The UF membrane used in this study allowed free access to soluble compounds with small molecular weight (e.g., VC and its oxides), which could induce fading of the color of the $\mathrm{KMnO}_{4}$ solution but entrapped CS and SeNPs. After the UF process, monodisperse CS-SeNPs were obtained with an average size of around $60 \mathrm{~nm}$, as shown in Figure 1A. Some characteristic peaks $(1.37,11.22$, and $12.49 \mathrm{keV})$ presented in the EDS spectra of SeNPs were identified as Se $L_{\alpha}$, Se $K_{\alpha}$, and Se $K_{\beta}$ signals, respectively, confirming the elemental nature of these nanoparticles (Figure 1B). More importantly, SeNPs were stable when the soluble byproducts were removed by UF, as evidenced by the stable size of SeNPs and the decreasing ability of UF to induce fading of the $\mathrm{KMnO}_{4}$ solution (Figure 1C). This was associated with a high zeta-potential of CS-SeNPs $(+31.2 \sim+38.5 \mathrm{mV})$, as compared with that of bare SeNPs $(-4.3 \sim-4.2 \mathrm{mV})$ (Figure 1D). Evidently, the surface decoration by CS significantly elevated the zeta-potential of SeNPs, which might be partly attributed to the positively charged $-\mathrm{NH}^{3+}$ groups in $\mathrm{CS}[15,16,33]$. This might guarantee the stability of SeNPs throughout the UF process. In short, UF is usually faster than dialysis and might retain the shape, size, and structure of SeNPs whiole removing byproducts. It might allow a rapid preparation of SeNPs. 

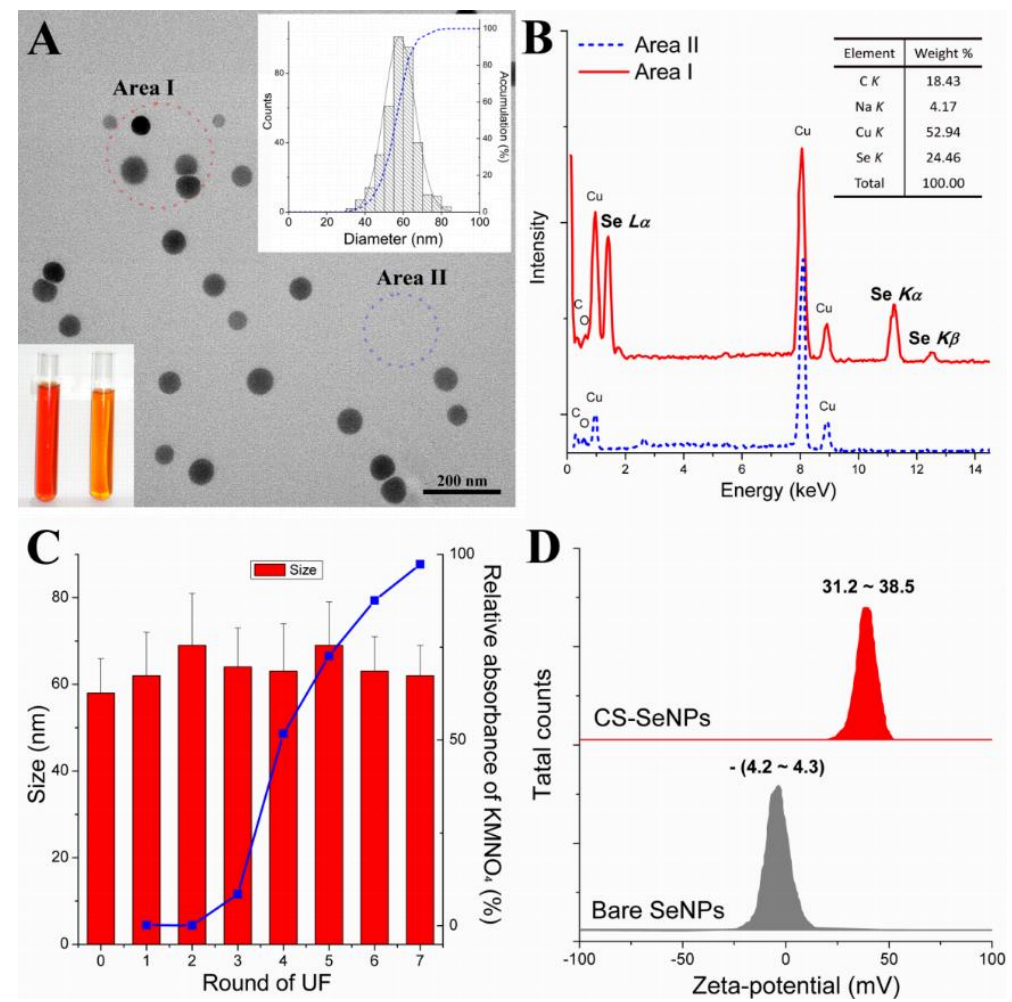

Figure 1. Physicochemical characteristics of CS-SeNPs. (A) TEM image, appearance, and size distribution of CS-SeNPs. (B) Typical EDS spectra of CS-SeNPs (measured at Area I, Figure 1A) and elemental composition (inset). (C) Size of SeNPs after rounds of ultra-filtration (UF) and absorbance (measured at $525 \mathrm{~nm}$ ) of a $\mathrm{KMnO}_{4}$ solution mixed with corresponding UF permeates. (D) Zeta-potentials of CS-SeNPs (UF Round 0-6) and of bare SeNPs.

\subsection{Antioxidant Capacity of CS-SeNPs Determined by the ORAC Methodology}

The ORAC assay $[23,24]$ was performed to estimate the total antioxidant potential of the Se samples. Trolox and V were used as referenced antioxidant compounds. As shown in Figure 2, the fluorescence was stable in the dark for 200 min without AAPH (indicated as AAPH-) but it was strongly weakened by the addition of AAPH (indicated as AAPH+). The fluorescence decay induced by AAPH, however, could be delayed by antioxidants. Trolox, VC, and CS-SeNPs, as presented in Figure 2, were able to hinder the APPH-induced fluorescence decay in a dose-dependent manner, whereas sodium selenite $(6.92-104 \mathrm{mg} / \mathrm{L})$ showed little inhibition due to its high chemical valence (Figure 2C).

To evaluate the antioxidant ability of the tested samples, the relative net AUC of each sample was plotted as a function of concentration (Figure 2F), followed by the calculation of the ORAC results, as shown in Table 2. It was found that the antioxidant abilities of the tested samples varied. According to the results of the ORAC assay, the antioxidant ability of the samples was: Trolox $>$ VC $>$ CS-SeNPs $>$ CS $>$ selenite, consistent with the order of chemical valence of Se. The ORAC of CS-SeNPs was around 1/7 of that of VC and approximately $1 / 20$ of that of Trolox. This indicates an acceptable antioxidant capacity of the SeNPs colloid. In the colloid, the population of SeNPs was small, as only about $20 \%$ of the weight of the lyophilized CS-SeNPs could be identified as Se (measured by ICP-MS [20]). However, the ORAC of CS-SeNPs was much greater than that of CS (Table 2). SeNPs might significantly improve the ORAC of CS-SeNPs, though the ORAC of these nanoparticles by themselves was difficult to measure, due to their very limited stability $[15,16]$. 

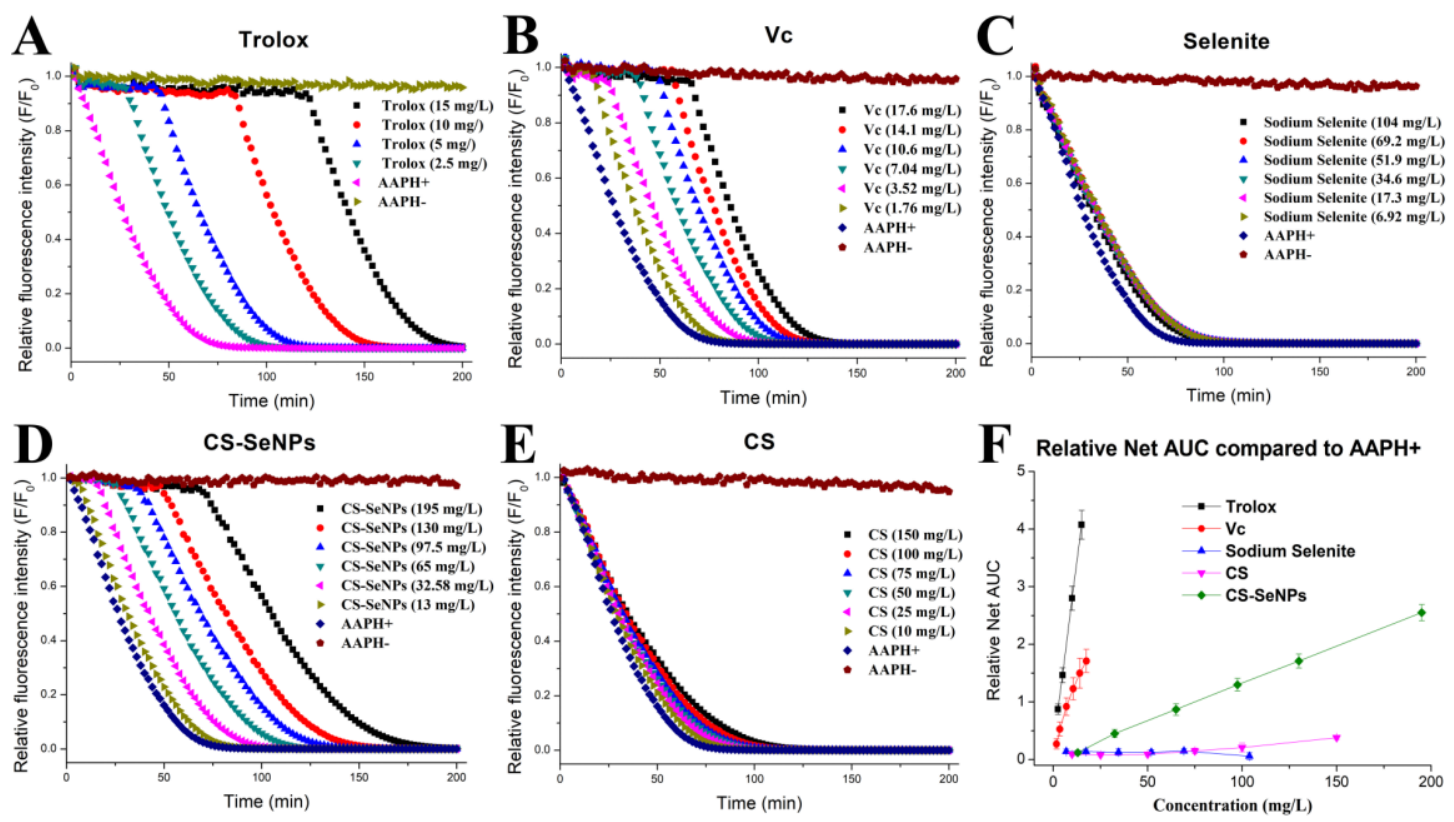

Figure 2. Effect of (A) Trolox, (B) ascorbic acid (VC), (C) sodium selenite, (D) CS-SeNPs colloid, and (E) $\mathrm{CS}$ on fluorescein consumption induced by AAPH and (F) dependence of the relative net area under the curve (AUC) upon the concentration of the compounds examined.

Table 2. Oxygen radical absorbance capacity (ORAC) results $(n=3)$.

\begin{tabular}{ccc}
\hline Sample & $\begin{array}{c}\text { ORAC }^{\mathbf{1}} \\
\text { (mg Trolox/100 } \mathbf{~ m g )}\end{array}$ & $\begin{array}{c}\text { Relative ORAC } \\
\mathbf{( \% )}\end{array}$ \\
\hline Trolox & 100 & 100 \\
VC & $35.16 \pm 3.54$ & 35.16 \\
Selenite & $<0.001$ & $<0.001$ \\
CS-SeNPs & $5.10 \pm 0.22$ & 5.10 \\
CS & $0.75 \pm 0.11$ & 0.75 \\
\hline
\end{tabular}

${ }^{1}$ Values evaluated as described in the experimental section. Values represent the weight $(\mathrm{mg})$ of Trolox that produces the same effect as $100 \mathrm{mg}$ of a tested sample. ${ }^{2}$ Values represent the ORAC of a sample compared with that of Trolox.

\subsection{Free-Radical Scavenging Ability of CS-SeNPs}

Many liver diseases are accompanied by an excess of radical oxygen species (ROS), which can result in oxidative damage to proteins and lipids in the body. Some saccharide- or protein-decorated SeNPs were reported to be able to clear free radicals, though in these studies, the stabilizer-SeNPs were regarded as a whole when evaluating their radical-scavenging potential $[33,37,38]$. However, the free-radical scavenging abilities of the stabilizers should be taken into consideration when measuring this property for SeNPs combined with a stabilizer. Besides, other reference compounds need to be studied at the same time, as they could help to evaluate the potential of SeNPs in clearing free radicals. Nonetheless this was not done in many studies [30,33,37,38].

Herein, $\bullet$ DPPH, $\bullet \mathrm{O}_{2}{ }^{-}$and $\bullet \mathrm{OH}^{-}$were utilized as model free radicals to evaluate the radical scavenging activities of CS-SeNPs, CS, sodium selenite, and VC. As shown in Figure 3, the CS-SeNPs colloid was able to remove all the three free radicals in a dose-dependent fashion, with scavenging ability of $1 / 7(\bullet \mathrm{DPPH}), 1 / 3\left(\bullet \mathrm{O}_{2}^{-}\right)$, and $1 / 5\left(\bullet \mathrm{OH}^{-}\right)$of that of VC. CS-SeNPs presented a stronger activity than sodium selenite in clearing $\bullet \mathrm{DPPH}$ and $\bullet \mathrm{O}_{2}{ }^{-}$, while they were not superior to selenite in scavenging $\bullet \mathrm{OH}^{-}$(Figure 3 and Table 3 ). This suggests that the potential of CS-SeNPs in reducing free radicals is complex. In addition, great differences in radical scavenging capacities could be found between CS and CS-SeNPs (Table 3). SeNPs might greatly contribute to the radical scavenging capacity 
of CS-SeNPs, when considering the weak potential of CS in cleaning these free radicals. This could be partly attributed to the low chemical valence and the vast specific surface area of these nanoparticles.
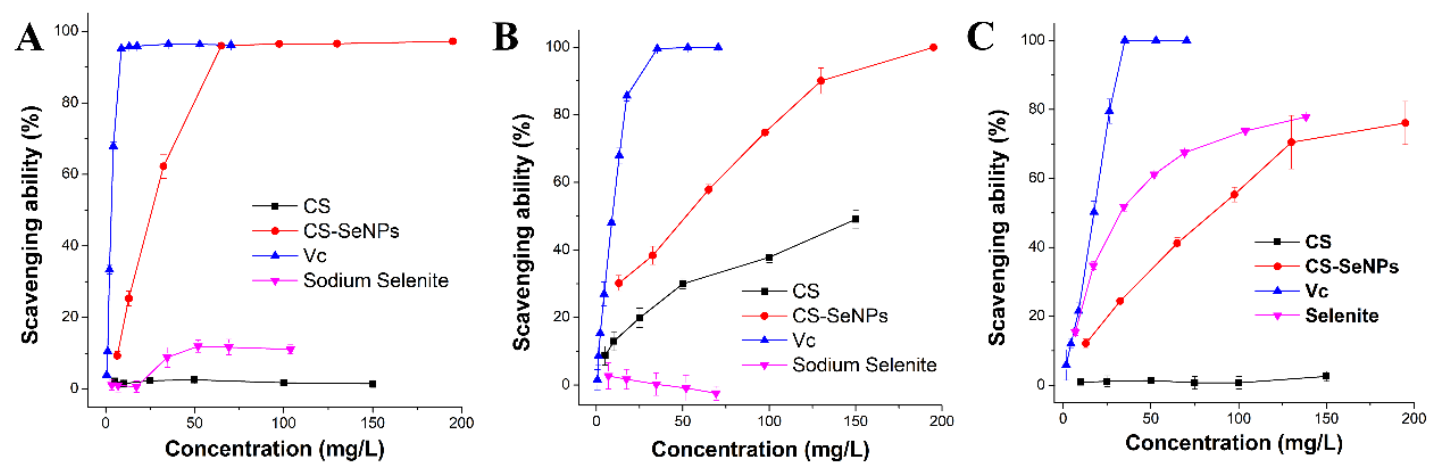

Figure 3. Free-radical scavenging activities against (A) DPPH $(\bullet \mathrm{DPPH}),(\mathbf{B})$ superoxide anion $\left(\bullet \mathrm{O}_{2}^{-}\right)$, and $(\mathbf{C})$ hydroxyl $\left(\bullet \mathrm{OH}^{-}\right)$radicals.

Table 3. $\mathrm{EC}_{50}$ of the free-radical scavenging ability $(\mathrm{mg} / \mathrm{L}, n=3)$ of the tested compounds.

\begin{tabular}{ccccc}
\hline Free Radical & VC & Sodium selenite & CS & CS-SeNPs \\
\hline$\bullet \mathrm{DPPH}$ & $2.90 \pm 0.04$ & $>>150$ & $>>150$ & $20.2 \pm 0.6$ \\
$\bullet \mathrm{O}_{2}^{-}$ & $5.79 \pm 1.0$ & $>>150$ & $>150$ & $17.5 \pm 0.6$ \\
$\bullet \mathrm{OH}^{-}$ & $15.0 \pm 1.2$ & $34.8 \pm 1.3$ & $>>150$ & $75.1 \pm 6.1$ \\
\hline
\end{tabular}

Note: $\mathrm{EC}_{50}$, concentration for $50 \%$ of maximal effect.

\subsection{Hepatoprotection by Dried CS-SeNPs against Con A}

\subsubsection{Dried CS-SeNPs Powder Used as a SeNPs Sample}

The CS-SeNPs colloid is unavailable for commercial application in oral administration systems due to its low stability $[15,16]$. In some previous studies $[15,16]$, the CS-SeNPs colloid alone or mixed with additional CS solution, was spray-dried to prepare a dried CS-SeNPs powder for better storage stability and larger application in the clinic. In this study, UF-purified CS-SeNPs were used to prepare a dried CS-SeNPs powder sample containing $30 \mathrm{mg} / \mathrm{kg}$ of Se (measured by ICP-MS [22]). The dried CS-SeNPs powder was utilized to evaluate the protective potential of SeNPs against Con-A-induced liver injury.

Oral administration of CS-SeNPs powder $(0.6,1.2,3.6 \mathrm{mg} / \mathrm{kg}$ bw, each day) to mice for 35 days was used to simulate sub-chronic Se consumption by humans. These doses were equal to 18, 36, and $108 \mu \mathrm{g}(\mathrm{Se}) / \mathrm{kg}$ bw in terms of Se dose, respectively, according to the equivalent dose conversion of mice to human $(\approx 12: 1)$ based on body surface area $[25,39]$. Considering the body weight of a human adult (generally $60 \mathrm{~kg}$ ), the daily Se doses $(1.5,3$, and $9 \mu \mathrm{g}$ Se/kg bw) for humans could actually be 90, 180, and $540 \mu \mathrm{g}$ Se per day, which meets the human requirements of adequate or super-nutritional Se [1-3].

\subsubsection{Growth and Viscera Status of KM Mice}

The biosafety of SeNPs should be taken into account before exploring their potential in the clinic. As previously reported, SeNPs were much safer when compared with selenite $[2,15,16]$. Herein, mice were given dried CS-SeNPs at three doses $\left(0.6,1.2,3.6 \mathrm{mg} / \mathrm{kg}\right.$ bw) well below the $\mathrm{LD}_{50}[15,16]$. The body weight of the mice was recorded to monitor their growth, showing that the growth was comparable among the animals throughout the experiment. Besides, the viscera indexes of heart, spleen, kidney, and thymus were normal among all groups of mice, except for that of liver. Con-A injection led to hepatic edema, characterized by a significantly higher liver index ( $p<0.05$, Model versus Control), as 
presented in Figure 4. However, this could be prevented by the oral administration of GA or dried CS-SeNPs powder, indicating the hepatoprotective potential of CS-SeNPs.

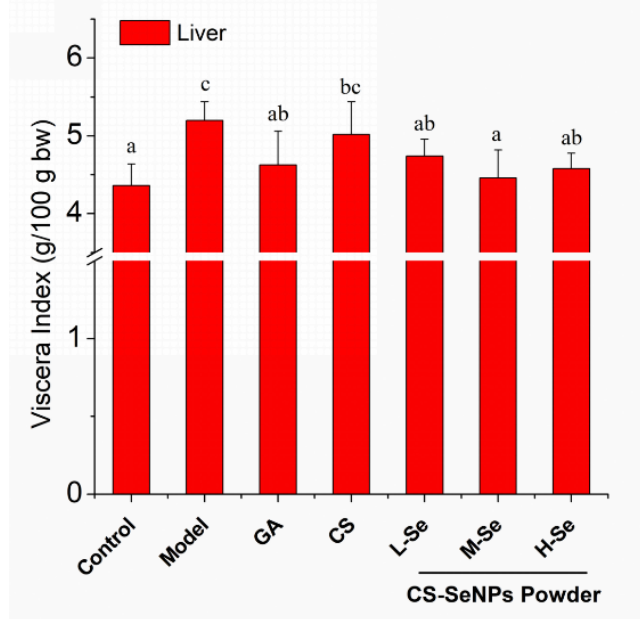

Figure 4. Liver index of KM mice, defined as the ratio of live weight to body weight. ${ }^{\mathrm{a}-\mathrm{c}}$ Means within a panel with different letters differ significantly.

\subsubsection{Histological Assessment of Hepatic Damage}

To evaluate the protective activity of the Se supplement against Con-A-caused liver injury, mice liver sections were observed by microscopy after H\&E staining. As illustrated in Figure 5B, severe hepatic damage, including ballooning degeneration, hydropic degeneration, pyknotic nuclei, lytic necrosis, and inflammatory cell infiltration, was observed $8 \mathrm{~h}$ after Con-A-injection, as compared with the Control (Figure 5A), consistent with previous studies $[27,28]$. However, the hepatic injury could be relieved by the oral administration of GA or dried CS-SeNPs, as evidenced by the amelioration of the aforementioned injuries, especially cellular necrosis (Figure 5C-G). Additionally, the lesions were scored blindly by a pathologist to grade the liver injury, as described in the Materials and Methods section. The results, presented in Figure $5 \mathrm{H}$, indicated that CS-SeNPs were able to protect the mice from Con-A-induced liver injury in a dose-dependent manner. The significant difference between the CS group and the M-Se group $(p<0.05)$ suggested an essential contribution of SeNPs to liver protection by dried CS-SeNPs.
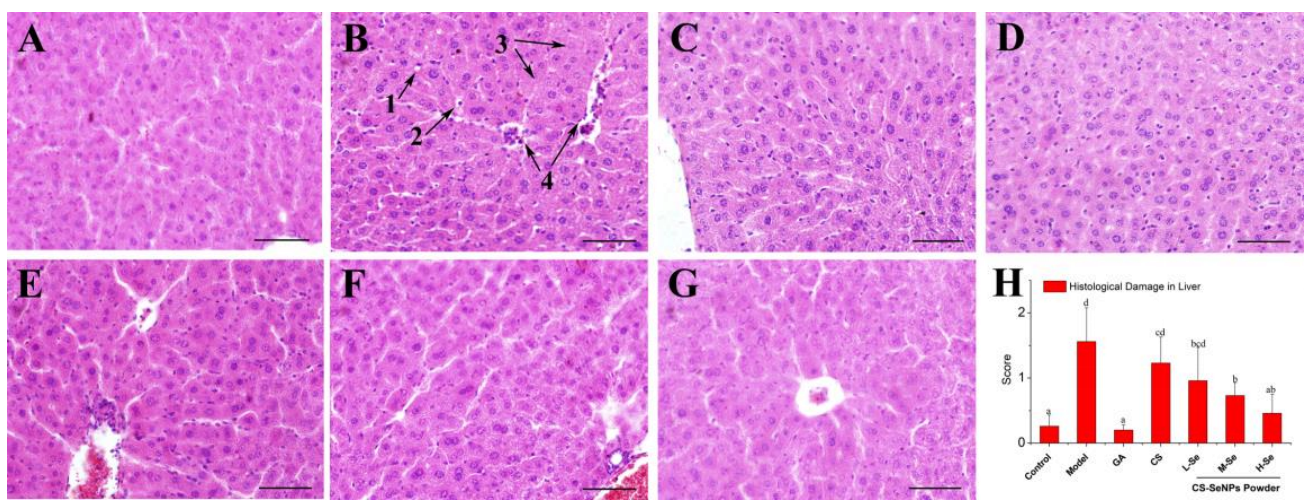

Figure 5. Histology of liver sections upon hematoxylin and eosin (H\&E) staining 200×. (A) Normal control, (B) Model, (C) GA, (D) CS, (E) L-Se, (F) M-Se, (G) H-Se, and (H) histological damage score of each group. Scale bars represents $25 \mu \mathrm{m}$. Arrows: 1, ballooning degeneration; 2 , hydropic degeneration; 3 , lytic necrosis; 4 , inflammatory cell infiltration. ${ }^{\text {a-d }}$ Means within a panel with different letters differ significantly. 


\subsubsection{Se Retention}

Se deposition in mice bodies was monitored to study the Se-supplying ability of CS-SeNPs in mice. This might help to investigate the role of SeNPs within the CS-SeNPs powder in protecting the liver from Con-A-induced damage. As presented in Figure 6, the serum and hepatic Se levels in the Se-supplementation groups were significantly higher than those of other groups $(p<0.05)$, indicating that CS-SeNPs might enhance the Se stock in the animals. This is in line with the reported efficient Se-retention capacity of some SeNPs stabilized by other macro-molecules $[2,3,25,40]$ or microorganisms [17], confirming the potential of nanoparticles in Se supplementation.
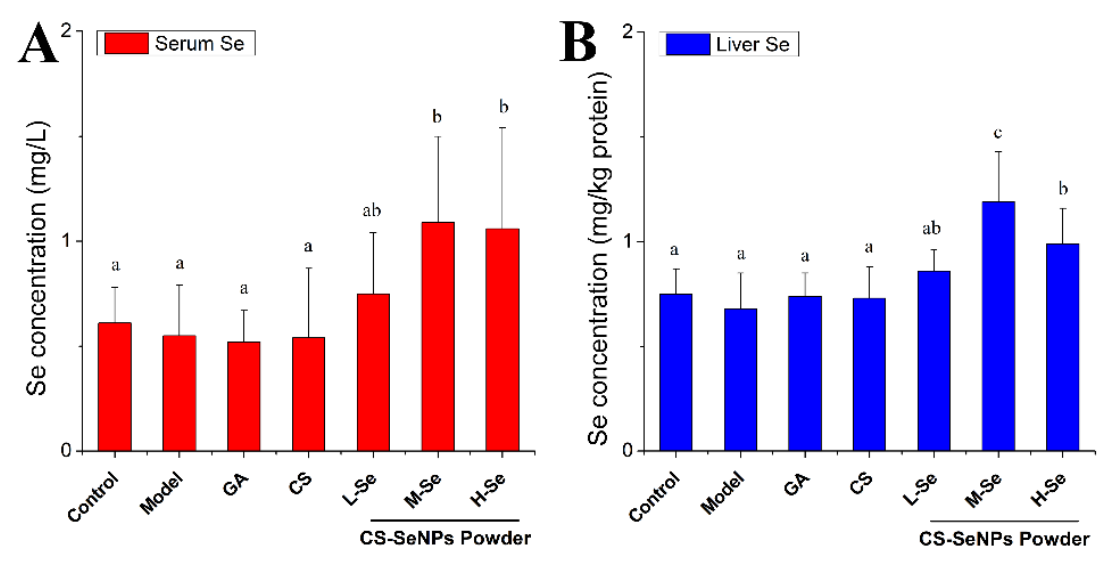

Figure 6. (A) Serum Se concentration and (B) hepatic Se level in KM mice. The administration modalities in each group are shown in Table 1. ${ }^{\mathrm{a}-\mathrm{c}}$ Means within a panel with different letters differed significantly $(p<0.05)$.

Se retention by extra Se supplementation needs to be discussed. One issue was the Se source. In consideration of the daily intake of adult KM mice (4-8 g diet/day each) [16,41] and the extremely low Se content of the feed $(<0.1 \mu \mathrm{g} \mathrm{Se} / \mathrm{g}$ diet) in this study, CS-SeNPs were actually the main source of Se. In addition, a great difference in Se levels was found between the M-Se group and the CS group $(p<0.05)$. It The SeNPs within the CS-SeNPs powder contributed to the enhancement of Se retention. Another issue was the dose of SeNPs. The daily doses of SeNPs used in this hepatoprotection study were acceptable, as they were far from those inducing a toxic status and were able to fulfill the need of adequate or super-nutritional Se according to Barnes [42] and Raines [43].

\subsubsection{Serum Levels of Liver Enzymes and GSH}

Serum enzymes, such as LDH, ALT, and AST, are generally recognized as essential bio-chemical markers of liver injury. They will present increased activity when hepatocytes are necrotic, due to their large leakage from the liver into the blood stream [44]. As presented in Table 4, serum ALT, AST, and LDH levels increased $8 \mathrm{~h}$ after intravenous Con A administration compared with the normal control group $(p<0.05)$, suggesting hepatocellular damage caused by Con A. However, pretreatment with GA $(10 \mathrm{mg} / \mathrm{kg} \mathrm{bw})$ or dried CS-SeNPs $(0.6,1.2,3.6 \mathrm{mg} / \mathrm{kg} \mathrm{bw})$ was able to protect the mice from Con-A-induced liver injury, as indicated by a significant decrease in these enzymes' levels as compared with the Model group $(p<0.05)$. Besides, the serum GSH concentration was also investigated, since a dramatic increase of these enzymes is often found in the damaged liver in the presence of oxidative stress $[18,29,45]$. The data shown in Table 4 indicate that CS-SeNPs $(1.2$ or $3.6 \mathrm{mg} / \mathrm{kg} \mathrm{bw})$ significantly attenuated Con-A-induced reduction of serum GSH ( $p<0.05$, versus Model). Possibly the antioxidant activity of CS-SeNPs contributes to hepatoprotection. 
Table 4. Serum alanine transaminase (ALT), aspartate transaminase (AST), lactic dehydrogenase (LDH), and glutathione (GSH) levels in $\mathrm{KM}$ mice $(n=10)$.

\begin{tabular}{ccccc}
\hline Group & ALT(U/L) & AST(U/L) & LDH (U/L) & GSH $(\mu \mathrm{mol} / \mathrm{L})$ \\
\hline Control & $10.3 \pm 2.1^{\mathrm{ab}}$ & $13.2 \pm 6.0^{\mathrm{a}}$ & $2929 \pm 396^{\mathrm{a}}$ & $17.4 \pm 7.8^{\mathrm{a}}$ \\
Model & $32.1 \pm 9.2^{\mathrm{c}}$ & $62.3 \pm 22.5^{\mathrm{b}}$ & $3655 \pm 331^{\mathrm{c}}$ & $5.9 \pm 4.9^{\mathrm{b}}$ \\
GA & $15.7 \pm 5.3^{\mathrm{ab}}$ & $10.7 \pm 6.0^{\mathrm{a}}$ & $3151 \pm 233^{\mathrm{ab}}$ & $7.2 \pm 5.4^{\mathrm{b}}$ \\
CS & $20.3 \pm 8.0^{\mathrm{b}}$ & $54.2 \pm 24.6^{\mathrm{b}}$ & $3411 \pm 185^{\mathrm{bc}}$ & $7.1 \pm 2.9^{\mathrm{b}}$ \\
L-Se & $16.4 \pm 6.1^{\mathrm{ab}}$ & $26.1 \pm 5.2^{\mathrm{a}}$ & $2920 \pm 349^{\mathrm{a}}$ & $8.2 \pm 3.3^{\mathrm{b}}$ \\
M-Se & $7.1 \pm 4.8^{\mathrm{a}}$ & $13.9 \pm 6.5^{\mathrm{a}}$ & $2983 \pm 277^{\mathrm{a}}$ & $17.4 \pm 8.4^{\mathrm{a}}$ \\
H-Se & $20.2 \pm 13.1^{\mathrm{b}}$ & $60.6 \pm 30.2^{\mathrm{b}}$ & $3342 \pm 517^{\mathrm{abc}}$ & $21.7 \pm 5.4^{\mathrm{a}}$ \\
\hline
\end{tabular}

${ }^{\mathrm{a}-\mathrm{c}}$ Values within a column not sharing a common superscript letter differ significantly at $p<0.05$.

Great difference in the levels of the aforementioned enzymes could be observed when comparing the M-Se group with the Control group ( $p<0.05$, shown in Table 4$)$, which attracted our attention. It suggested SeNPs play an essential role in protecting hepatocytes from liver necrosis caused by Con A. Similar superiority of CS-SeNPs to CS was also found when studying serum GSH levels. These results are in good agreement with the observed histopathological changes (Figures 4 and 5) and Se retention modification (Figure 6), suggesting that the hepatoprotection function of the CS-SeNPs powder may be greatly attributed to SeNPs.

\subsubsection{Antioxidant Activity in the Liver}

Oxidative stress is very common in hepatitis. It is often accompanied by the development of inflammatory liver injury induced by autoimmunity disorders [29,46]. In Con-A-induced acute liver injury, $\mathrm{T}$ and NKT cells are activated by Con A, producing inflammatory cytokines and chemokines $[29,46,47]$. These factors recruit and activate more immune cells which would attack hepatocytes, leading to severe necrosis $[46,47]$. Throughout the course of this process, oxidative burst occurs quickly and involves a rapid jump of ROS production, resulting in the oxidation of a diverse range of biological molecules, such as nucleic acids, lipids, and proteins [27,29]. The alleviation of the oxidative risk might be helpful for both ameliorating the oxidation-induced damage in cells and controlling the activation of critical signaling cascades such as protein kinases, cytokines, and transcription factors [6,27], finally protecting against hepatic necrosis and dysfunction.

The enhancement of serum GSH level by CS-SeNPs (shown in Table 4) indicated the possible antioxidant activity of the Se-supplement in animals. Herein, the antioxidant activity of CS-SeNPs in the liver was also studied. As shown in Table 5, Con A injection led to a potent oxidative stress characterized by an increase of TBARS and a decrease in GSH. It also led to the downregulation of some vital antioxidant enzymes including SOD, CAT, and GSH-Px. Apparently, the hepatic cells suffered from severe oxidative stress after the injection of Con A. However, the CS-SeNPs powder at the studied doses maintained GSH levels, reduced TBARS levels, and upregulated the levels of SOD, CAT, and GSH-Px, when compared with the Model group $(p<0.05)$. This powder $(1.2$ and $3.6 \mathrm{mg} / \mathrm{kg} \mathrm{bw})$ showed powerful antioxidant ability, comparable or superior to that of GA $(10 \mathrm{mg} / \mathrm{kg} \mathrm{bw})$. Its hepatoprotection mechanism might be different from that of some primary medicines such as cortisone (a hormone inhibiting the inflammatory process), while Se immunological modulation ability [1-3] could also take part in the protection. This deserves further investigation. 
Table 5. The levels of GSH, thiobarbituric acid-reactive substances (TBARS), superoxide dismutase (SOD), catalase (CAT), and glutathione peroxidase (GSH-Px) in mice liver $(n=10)$.

\begin{tabular}{|c|c|c|c|c|c|}
\hline Group & $\begin{array}{c}\text { GSH } \\
(\mu \mathrm{mol} / \mathrm{g} \text { prot})\end{array}$ & $\begin{array}{c}\text { TBARS } \\
(\mu \mathrm{mol} / \mathrm{g} \text { prot })\end{array}$ & $\begin{array}{c}\text { SOD } \\
\text { (U/g prot) }\end{array}$ & $\begin{array}{c}\text { CAT } \\
\text { (U/g prot) }\end{array}$ & $\begin{array}{l}\text { GSH-Px } \\
\text { (U/g prot) }\end{array}$ \\
\hline Control & $7.99 \pm 2.81^{\mathrm{ab}}$ & $1.13 \pm 0.35^{\mathrm{a}}$ & $243 \pm 39^{a}$ & $41.4 \pm 7.5^{\mathrm{ab}}$ & $473 \pm 146^{\mathrm{ab}}$ \\
\hline Model & $2.08 \pm 1,75^{\mathrm{c}}$ & $4.68 \pm 1.79^{c}$ & $154 \pm 22^{c}$ & $28.9 \pm 6.2^{\mathrm{a}}$ & $183 \pm 103^{c}$ \\
\hline GA & $3.26 \pm 2.01 \mathrm{bc}$ & $1.28 \pm 0.43^{\mathrm{a}}$ & $151 \pm 21^{\mathrm{c}}$ & $56.6 \pm 26.1^{b}$ & $399 \pm 58^{a b c}$ \\
\hline CS & $4.69 \pm 3.03^{a b c}$ & $3.22 \pm 1.06^{b c}$ & $184 \pm 20^{b c}$ & $30.3 \pm 10.9^{a}$ & $278 \pm 133^{b c}$ \\
\hline L-SeM & $2.37 \pm 1.82 b c$ & $1.44 \pm 0.50 \mathrm{ab}$ & $\mathrm{nt}$ & $34.6 \pm 13.2^{\mathrm{ab}}$ & $450 \pm 162^{a b}$ \\
\hline M-SeM & $7.91 \pm 3.81^{a b}$ & $0.96 \pm 0.50^{\mathrm{a}}$ & $240 \pm 34^{\mathrm{a}}$ & $50.4 \pm 13.9^{a b}$ & $519 \pm 97^{a}$ \\
\hline H-SeM & $9.10 \pm 3.56^{\mathrm{a}}$ & $1.44 \pm 1.06^{\mathrm{ab}}$ & $204 \pm 27^{a b}$ & $34.9 \pm 7.7^{\mathrm{ab}}$ & $461 \pm 114^{\mathrm{ab}}$ \\
\hline
\end{tabular}

a-c Values within a column not sharing a common superscript letter differed significantly at $p<0.05$. prot, protein; nt, not tested.

Some points needed to be discussed. The first regards the contributions of SeNPs and CS to the overall antioxidant ability of CS-SeNPs. CS $(1.2 \mathrm{mg} / \mathrm{kg}$ bw) did not improve the above-mentioned biomarkers, but dried CS-SeNPs powder containing an almost equal amount of CS was able to enhance the antioxidant status in mice, as shown by the decrease in TBARS and the upregulation of both SOD and GSH-Px ( $p<0.05$ versus Model). It is probable that SeNPs made a great contribution to the antioxidant activity of the CS-SeNPs powder in animals. The second point is the role of SeNPs in improving the antioxidant state in vivo. Se deposition (shown in Figure 6) and the intrinsic antioxidant potentials of SeNPs (presented in Tables 2 and 3) might partly explain the antioxidant ability of SeNPs in the liver, though the Se concentration achieved might have been too low to remove the oxidative stress directly. More importantly, SeNPs were efficient in boosting GSH-Px, which is a vital antioxidant enzyme that uses Se as an integral element of its catalytic sites. It is possible that Se retention by CS-SeNPs contributed greatly to the Se storage pool in the body [48], finally resulting in an enhancement of GSH-Px. The third point is the broad hepatoprotection of SeNPs. It was reported that SeNPs alone or combined with vitamins might protect animals from the hepatic injury caused by toxic chemicals (e.g, carbon tetrachloride [17], acetaminophen [18], and acrylamide [19]) or by pathogen infections (e.g, Schistosoma spp. [20]). These reports focused on the potential of SeNPs to enhance the redox state in vivo and showed that it really contributed to the hepatoprotection of SeNPs. In the present study, CS-SeNPs were able to protect mice from Con-A-induced autoimmune hepatitis by improving the redox status and enhancing the levels of SOD, CAT, and GSH-Px. SeNPs might play a passive role in protecting animals from liver diseases involving serious oxidative stress.

\section{Conclusions}

In this study, a rapid and simple method involving UF was introduced to prepare CS-SeNPs of around $60 \mathrm{~nm}$. The CS-stabilized SeNPs exhibited acceptable antioxidant activity and potent free-radical scavenging ability. A spray-dried CS-SeNPs powder was able to protect mice from Con-A-induced autoimmune liver injury, as indicated by the reduction of hepatic edema, amelioration of hepatocytes necrosis, and alleviation of the leakage of ALT, AST, and LDH from the hepatocytes into the blood stream. The hepatoprotective capacity of the dried CS-SeNPs powder might be partly attributed to the ability of this Se-supplement to improve Se retention, reducing TBARS, increasing GSH, and up-regulating SOD, CAT, and GSH-Px in the liver. SeNPs might contribute greatly to the antioxidant activity and hepatoprotective role of the CS-SeNPs. In summary, SeNPs stabilized by CS deserve being considered for further development as nutrient supplements or even nanomedicines that aim to defend against autoimmune-disorder-induced hepatic injury.

Author Contributions: Conceptualization, methodology, investigation, funding acquisition, and data curation, K.B. and B.H.; supervision, project administration, resources, K.B.; software, validation, formal analysis, and visualization, B.H. and J.H.; writing-original draft preparation, writing-review, and editing, K.B. and W.H. All authors have read and agreed to the published version of the manuscript. 
Funding: This research was funded by the Scientific Research Foundation of Third Institute of Oceanography, Ministry of Natural Resources, People's Republic of China (No. 2019014), the Scientific and Technological Project of Fujian Province, People's Republic of China (No. 2016N0018), and the Science and Technology Major Projects of Fujian province, People's Republic of China (No. 2014NZ0001). We also thank the support from the Marine Economic Innovation and Development Demonstration Project, Beihai, the 15th Five-Year Plan for Economic and Social Development of the People's Republic of China (No. Bhsfs007-ss-1). The study was also supported by a Scientific and Technological Project of Fujian Province (No. 2017N0017).

Acknowledgments: We thank Yanhua Mu from Shenyang Pharmaceutical University for her great help in the animal experiments. We also acknowledge Binbin Xu and Yuanfei Wu (Xiamen University, China) and Li Gu (Third Institute of Oceanography, MNR, China) for their assistance when performing TEM and EDS.

Conflicts of Interest: The authors declare no conflict of interest.

\section{Abbreviations}

AAPH

ALT

AST

AUC

bw

Con A

CS

CS-SeNPs

$\mathrm{DPPH}$

-DPPH

$\mathrm{EC}_{50}$

EDS

GA

GSH

GSH-Px

ICP-MS

i.p,

i.v,

LDH

KM

$\mathrm{KMnO}_{4}$

$\mathrm{LD}_{50}$

MW

MWCO

$\bullet \mathrm{O}_{2}{ }^{-}$

- $\mathrm{OH}^{-}$

ORAC

$\mathrm{RH}$

ROS

SA

Se

SeNPs

SOD

SPF

TBARS

TEM

Trolox

UF

Vc
2,2'-Azobis-(2-amidinopropane)-dihydrochloride

alanine transaminase

aspartate transaminase

area under the curve

body weight

concanavalin A

chitosan

chitosan-stabilized selenium nanopartilcels

1,1-diphenyl-2-picrylhydrazyl

1,1-diphenyl-2-picrylhydrazyl radical

concentration for $50 \%$ of maximal effect

energy-dispersive $\mathrm{X}$-ray spectroscopy

glycyrrhizic acid

glutathione

glutathione peroxidase

inductively coupled plasma mass spectrometry

intraperitoneal

intravenously

lactic dehydrogenase

Kunming

potassium permanganate

median lethal dose

molecular weight

molecular weight cut-off

superoxide anion radical

hydroxyl radical

oxygen radical absorbance capacity

relative humidity

radical oxygen species

salicylic acid

selenium

selenium nanoparticles

superoxide dismutase

specifc-pathogen-free

thiobarbituric acid-reactive substances

transmission electron microscopy

6-hydroxy-2,5,7,8-tetramethylchroman-2-carboxylic acid

ultra-filtration

ascorbic acid 


\section{References}

1. Navarro-Alarcon, M.; Cabrera-Vique, C. Selenium in food and the human body: A review. Sci. Total Environ. 2008, 400, 115-141. [CrossRef]

2. Zhang, J.; Spallholz, J.E. Toxicity of selenium compounds and nano-selenium particles. In General, Applied and Systems Toxicology, 2nd ed.; Casciano, D.A., Sahu, S.C., Eds.; John Wiley \& Sons: Hoboken, NJ, USA, 2011; pp. 787-802.

3. Hosnedlova, B.; Kepinska, M.; Skalickova, S.; Fernandez, C.; Ruttkay-Nedecky, B.; Peng, Q.; Baron, M.; Melcova, M.; Opatrilova, R.; Zidkova, J.; et al. Nano-selenium and its nanomedicine applications: A critical review. Int. J. Nanomed. 2018, 13, 2107-2128. [CrossRef] [PubMed]

4. Schrauzer, G.N.; Surai, P.F. Selenium in human and animal nutrition: Resolved and unresolved issues. A partly historical treatise in commemoration of the fiftieth anniversary of the discovery of the biological essentiality of selenium, dedicated to the memory of Klaus Schwarz (1914-1978) on the occasion of the thirtieth anniversary of his death. Crit. Rev. Biotechnol. 2009, 29, 2-9. [CrossRef] [PubMed]

5. Shin, J.W.; Wang, J.H.; Kim, H.G.; Park, H.J.; Bok, H.S.; Son, C.G. CGX, a traditional Korean medicine ameliorates concanavalin A-induced acute liver injury. Food Chem. Toxicol. 2010, 48, 3308-3315. [CrossRef]

6. Zhao, M.; Chen, J.; Zhu, P.; Fujino, M.; Takahara, T.; Toyama, S.; Tomita, A.; Zhao, L.; Yang, Z.; Hei, M.; et al. Dihydroquercetin (DHQ) ameliorated concanavalin A-induced mouse experimental fulminant hepatitis and enhanced HO-1 expression through MAPK/Nrf2 antioxidant pathway in RAW cells. Int. Immunopharmacol. 2015, 28, 938-944. [CrossRef] [PubMed]

7. Zhao, J.; Chen, H.; Li, Y. Protective effect of bicyclol on acute alcohol-induced liver injury in mice. Eur. J. Pharmacol. 2008, 586, 322-331. [CrossRef] [PubMed]

8. Messarah, M.; Klibet, F.; Boumendjel, A.; Abdennour, C.; Bouzerna, N.; Boulakoud, M.S.; Feki, A.E. Hepatoprotective role and antioxidant capacity of selenium on arsenic-induced liver injury in rats. Exp. Toxicol. Pathol. 2012, 64, 167-174. [CrossRef]

9. Taskin, E.; Dursun, N. Recovery of adriamycin induced mitochondrial dysfunction in liver by selenium. Cytotechnology 2015, 67, 977-986. [CrossRef]

10. Yao, L.; Du, Q.; Yao, H.; Chen, X.; Zhang, Z.; Xu, S. Roles of oxidative stress and endoplasmic reticulum stress in selenium deficiency-induced apoptosis in chicken liver. Biometals 2015, 28, 255-265. [CrossRef]

11. Wang, W.; Zhang, T.; Lin, H.; Chang, Y.; Xing, J. Role of Hydrogen Sulfide on Autophagy in Liver Injuries Induced by Selenium Deficiency in Chickens. Biol. Trace Elem. Res. 2017, 175, 194-203. [CrossRef]

12. Fu, X.; Zhong, Z.; Hu, F.; Zhang, Y.; Li, C.; Yan, P.; Feng, L.; Shen, J.; Huang, B. The protective effects of selenium-enriched Spirulina platensis on chronic alcohol-induced liver injury in mice. Food Funct. 2018, 9 , 3155-3165. [CrossRef] [PubMed]

13. Darvesh, A.S.; Bishayee, A. Selenium in the prevention and treatment of hepatocellular carcinoma. Anti-Cancer Agents Med. Chem. 2010, 10, 338-345. [CrossRef] [PubMed]

14. Hu, Y.J.; Chen, Y.; Zhang, Y.Q.; Zhou, M.Z.; Song, X.M.; Zhang, B.Z.; Luo, L.; Xu, P.M.; Zhao, Y.N.; Zhao, Y.B.; et al. The protective role of selenium on the toxicity of cisplatin-contained chemotherapy regimen in cancer patients. Biol. Trace Elem. Res. 1997, 56, 331-341. [CrossRef] [PubMed]

15. Bai, K.; Hong, B.; He, J.; Hong, Z.; Tan, R. Preparation and antioxidant properties of selenium nanoparticles-loaded chitosan microspheres. Int. J. Nanomed. 2017, 12, 4527-4539. [CrossRef]

16. Bai, K.; Hong, B.; Hong, Z.; Sun, J.; Wang, C. Selenium nanoparticles-loaded chitosan/citrate complex and its protection against oxidative stress in D-galactose-induced aging mice. J. Nanobiotechnol. 2017, 15, 92-105. [CrossRef]

17. Li, B.; Li, D.; Jing, W.; Fan, J.; Dahms, H.U.; Lee, S.C.; Wang, L. Biogenic selenium and its hepatoprotective activity. Sci. Rep. 2017, 7, 15627. [CrossRef]

18. Amin, K.A.; Hashem, K.S.; Alshehri, F.S.; Awad, S.T.; Hassan, M.S. Antioxidant and Hepatoprotective Efficiency of Selenium Nanoparticles Against Acetaminophen-Induced Hepatic Damage. Biol. Trace Elem. Res. 2017, 175, 136-145. [CrossRef]

19. Hamza, R.Z.; Al-Motaan, S.E.; Malik, N. Protective and Antioxidant Role of Selenium Nanoparticles and Vitamin C Against Acrylamide Induced Hepatotoxicity in Male Mice. Int. J. Pharmacol. 2019, 15, 664-674. [CrossRef] 
20. Dkhil, M.A.; Bauomy, A.A.; Diab, M.S.M.; Al-Quraishy, S. Protective role of selenium nanoparticles against Schistosoma mansoni-induced hepatic injury in mice. Biomed. Res. 2016, 27, 214-219.

21. Rinaudo, M. Chitin and chitosan: Properties and applications. Prog. Polym. Sci. 2006, 31, 603-632. [CrossRef]

22. Dufailly, V.; Noël, L.; Guérin, T. Determination of chromium, iron and selenium in foodstuffs of animal origin by collision cell technology, inductively coupled plasma mass spectrometry (ICP-MS), after closed vessel microwave digestion. Anal. Chim. Acta 2006, 565, 214-221. [CrossRef]

23. Alarcón, E.; Campos, A.M.; Edwards, A.M.; Lissi, E.; López-Alarcón, C. Antioxidant capacity of herbal infusions and tea extracts: A comparison of ORAC-fluorescein and ORAC-pyrogallol red methodologies. Food Chem. 2008, 107, 1114-1119. [CrossRef]

24. Atala, E.; Vásquez, L.; Speisky, H.; Lissi, E.; López-Alarcón, C. Ascorbic acid contribution to ORAC values in berry extracts: An evaluation by the ORAC-pyrogallol red methodology. Food Chem. 2009, 113, 331-335. [CrossRef]

25. Bai, K.; Hong, B.; Huang, W.; He, J. Selenium-Nanoparticles-Loaded Chitosan/Chitooligosaccharide Microparticles and Their Antioxidant Potential: A Chemical and In Vivo Investigation. Pharmaceutics 2020, 12, 43. [CrossRef]

26. Peralta, E.; Roab, G.; Hernandez-Servin, J.A.; Romero, R.; Balderas, P.; Natividad, R. Hydroxyl Radicals quantification by UV spectrophotometry. Electrochim. Acta 2014, 129, 137-141. [CrossRef]

27. Wang, K.; Song, Z.; Wang, H.; Li, Q.; Cui, Z.; Zhang, Y. Angelica sinensis polysaccharide attenuates concanavalin A-induced liver injury in mice. Int. Immunopharmacol. 2016, 31, 140-148. [CrossRef]

28. Anraku, M.; Hiraga, A.; Iohara, E.; Uekama, K.; Tomida, H.; Otagiri, M.; Hirayama, F. Preparation and antioxidant activity of PEGylated chitosans with different particle sizes. Int. J. Biol. Macromol. 2014, 70, 64-69. [CrossRef]

29. Wang, F.; Xue, Y.; Yang, J.; Lin, F.; Sun, Y.; Li, T.; Wu, C. Hepatoprotective effect of apple polyphenols against concanavalin A-induced immunological liver injury in mice. Chem. Biol. Interact 2016, 258, 159-165. [CrossRef]

30. Kong, H.; Yang, J.; Zhang, Y.; Fang, Y.; Nishinari, K.; Phillips, G.O. Synthesis and antioxidant properties of gum arabic-stabilized selenium nanoparticles. Int. J. Biol. Macromol. 2014, 65, 155-162. [CrossRef]

31. Chen, H.; Shin, D.W.; Nam, J.G.; Kwon, K.W.; Yoo, J.B. Selenium nanowires and nanotubes synthesized via a facile template-free solution method. Mater. Res. Bull. 2010, 45, 699-704. [CrossRef]

32. Zheng, J.S.; Zheng, S.Y.; Zhang, Y.B.; Zheng, W.; Yang, F.; Chen, T. Sialic acid surface decoration enhances cellular uptake and apoptosis-inducing activity of selenium nanoparticles. Colloid Surf. B 2011, 83, 183-187. [CrossRef] [PubMed]

33. Zhang, C.; Zhai, X.; Zhao, G.; Ren, F.; Leng, X. Synthesis, characterization, and controlled release of selenium nanoparticles stabilized by chitosan of different molecular weights. Carbohydr. Polym. 2015, 134, 158-166. [CrossRef] [PubMed]

34. Akbulut, O.; Mace, C.R.; Martinez, R.V.; Kumar, A.A.; Nie, Z.; Patton, M.R.; Whitesides, G.M. Separation of nanoparticles in aqueous multiphase systems through centrifugation. Nano Lett. 2012, 12, 4060-4064. [CrossRef] [PubMed]

35. Srivastava, N.; Mukhopadhyay, M. Green synthesis and structural characterization of selenium nanoparticles and assessment of their antimicrobial property. Bioprocess Biosyst. Eng. 2015, 38, 1723-1730. [CrossRef] [PubMed]

36. Ramamurthy, C.H.; Sampath, K.S.; Arunkumar, P.; Suresh, K.M.; Sujatha, V.; Thirunavukkarasu, C. Green synthesis and characterization of selenium nanoparticles and its augmented cytotoxicity with doxorubicin on cancer cells. Bioprocess Biosyst. Eng. 2013, 36, 1131-1139. [CrossRef] [PubMed]

37. Zhai, X.; Zhang, C.; Zhao, G.; Stoll, S.; Ren, F.; Leng, X. Antioxidant capacities of the selenium nanoparticles stabilized by chitosan. J. Nanobiotechnol. 2017, 15, 4-15. [CrossRef]

38. Huang, B.; Zhang, J.; Hou, J.; Chen, C. Free radical scavenging efficiency of Nano-Se in vitro. Free Radic. Biol. Med. 2003, 35, 805-813. [CrossRef]

39. Reagan-Shaw, S.; Nihal, M.; Ahmad, N. Dose translation from animal to human studies revisited. FASEB J. 2007, 22, 659-661. [CrossRef]

40. Hu, C.H.; Li, Y.L.; Xiong, L.; Zhang, H.M.; Song, J.; Xia, M.S. Comparative effects of nano elemental selenium and sodium selenite on selenium retention in broiler chickens. Anim. Feed Sci. Technol. 2012, 177, $204-210$. [CrossRef] 
41. Dai, H.C.; Long, L.Q.; Zhang, X.W.; Zhang, W.M.; Wu, X.X. Cloning and expression of the duck leptin gene and the effect of leptin on food intake and fatty deposition in mice. J. Anim. Sci. 2007, 20, 850-855. [CrossRef]

42. Barnes, K.M.; Evenson, J.K.; Raines, A.M.; Sunde, R.A. Transcript Analysis of the Selenoproteome Indicates That Dietary Selenium Requirements of Rats Based on Selenium-Regulated Selenoprotein mRNA Levels Are Uniformly Less Than Those Based on Glutathione Peroxidase Activity. J. Nutr. 2009, 139, 199-206. [CrossRef]

43. Raines, A.M.; Sunde, R.A. Selenium toxicity but not deficient or supernutritional selenium status vastly alters the transcriptome in rodents. BMC Genom. 2011, 12, 26-40. [CrossRef]

44. El-Demerdash, F.; Yousef, M.; El-Naga, N. Biochemical study on the hypoglycemic effects of onion and garlic in alloxan-induced diabetic rats. Food Chem. Toxicol. 2005, 43, 57-63. [CrossRef] [PubMed]

45. Kodai, S.; Takemura, S.; Minamiyama, Y.; Hai, S.; Yamamoto, S.; Kubo, S.; Yoshida, Y.; Niki, E.; Okada, S.; Hirohashi, K.; et al. S-allyl cysteine prevents CCl4-induced acute liver injury in rats. Free Radic. Res. 2007, 41, 489-497. [CrossRef] [PubMed]

46. Li, G.; Chen, M.J.; Wang, C.; Nie, H.; Huang, W.J.; Yuan, T.D.; Sun, T.; Shu, K.G.; Wang, C.F.; Gong, Q.; et al. Protective effects of hesperidin on concanavalin A-induced hepatic injury in mice. Int. Immunopharmacol. 2014, 21, 406-411. [CrossRef] [PubMed]

47. Nakashima, H.; Kinoshita, M.; Nakashima, M.; Habu, Y.; Shono, S.; Uchida, T.; Shinomiya, N.; Seki, S. Superoxide produced by Kupffer cells is an essential effector in concanavalin A-induced hepatitis in mice. Hepatology 2008, 48, 1979-1988. [CrossRef]

48. Burk, R.F.; Hill, K.E.; Motley, A.D.; Winfrey, V.P.; Kurokawa, S.; Mitchell, S.L.; Zhang, W. Selenoprotein P and apolipoprotein E receptor-2 interact at the blood-brain barrier and also within the brain to maintain an essential selenium pool that protects against neurodegeneration. FASEB J. 2014, 28, 3579-3588. [CrossRef]

(C) 2020 by the authors. Licensee MDPI, Basel, Switzerland. This article is an open access article distributed under the terms and conditions of the Creative Commons Attribution (CC BY) license (http://creativecommons.org/licenses/by/4.0/). 